Check for updates

Cite this: RSC Adv., 2017, 7, 51485

\title{
Temperature- and frequency-dependent dielectric response and energy-storage performance in high (100)-oriented Sc doped $\left(\mathrm{Na}_{0.85} \mathrm{~K}_{0.15}\right)_{0.5} \mathrm{Bi}_{0.5} \mathrm{TiO}_{3}$ films
}

\begin{abstract}
Yunyi Wu, (D) $\dagger^{\text {*a }}$ Yonghong Hu, $\hat{\dagger}^{\mathrm{b}}$ Xiaohui Wang, ${ }^{\mathrm{c}}$ Caifu Zhong ${ }^{\mathrm{d}}$ and Longtu $\mathrm{Li}^{\mathrm{c}}$
Highly (100)-oriented $\left(\mathrm{Na}_{0.85} \mathrm{~K}_{0.15}\right)_{0.5} \mathrm{Bi}_{0.5} \mathrm{Ti}_{0.75} \mathrm{SC}_{0.25} \mathrm{O}_{3}$ (NKBT-Sc) films with thicknesses ranging from about 460 to $860 \mathrm{~nm}$ were grown by utilizing $\mathrm{TiO}_{2}$ layers engineering. Effects of $\mathrm{TiO}_{2}$ layers on dielectric properties and energy-storage performances of NKBT-Sc films were investigated in a wide temperature range and a wide frequency range. The $\mathrm{TiO}_{2}$ layers inserted alternately inside the NKBT-Sc films can enhance the (100) preferred degree of the film and it doesn't decrease with an increase in film thickness. Compared with NKBT-SC films without $\mathrm{TiO}_{2}$ layers, the $\mathrm{TiO}_{2}$-coated NKBT-SC films exhibit a great enhancement in electrical properties and energy-storage performance. The best dielectric properties with the largest dielectric constant $\left(\varepsilon_{r}\right)$ of about 782 and the lowest dielectric loss (tan $\delta$ ) of about 0.051 at $1 \mathrm{kHz}$, together with a maximum energy-density $(W)$ of about $22.7 \mathrm{~J} \mathrm{~cm}^{-3}$ and corresponding efficiency $(\eta)$ of about $51.5 \%$, were obtained at room temperature in the $860 \mathrm{~nm}$-thickness film with $\mathrm{TiO}_{2}$ layers coated alternately with NKBT-Sc layers. Moreover, energy-density and the corresponding efficiency of the $\mathrm{TiO}_{2}$-coated NKBT-Sc films varied slightly over a temperature range from $-150{ }^{\circ} \mathrm{C}$ to $150{ }^{\circ} \mathrm{C}$ as well as at a frequency range from $100 \mathrm{~Hz}$ to $6 \mathrm{kHz}$, meaning a greatly enhanced temperature dependent energy-storage stability and a frequency dependent energy-storage stability. In addition, leakage current density (J) of the $860 \mathrm{~nm}$-thickness $\mathrm{TiO}_{2}$-coated NKBT-Sc film was maintained at a relatively low value. This also means that it can work in a wide operating temperature. This much enhanced energy-storage density and good temperature stability make NKBT-Sc films to be a promising lead-free material for energy storage capacitor applications.
\end{abstract}

\author{
Received 10th September 2017 \\ Accepted 21st October 2017 \\ DOI: $10.1039 / c 7 r a 10068 j$ \\ rsc.li/rsc-advances
}

\section{Introduction}

With increasing requirements for compact electronics, ferroelectric thin films have attracted ever-growing interests in recent years due to their practical applications in energy harvesting and storage capacitors. ${ }^{1}$ The initial ferroelectric material utilized for commercial electronic devices was $\mathrm{Pb}(\mathrm{Zr}, \mathrm{Ti}) \mathrm{O}_{3}$ (PZT)-based owing to its strong electromechanical coupling performance. ${ }^{2,3}$ Bismuth sodium titanate, $\left(\mathrm{Na}_{0.5} \mathrm{Bi}_{0.5}\right) \mathrm{TiO}_{3}(\mathrm{NBT})$ is considered as a potential candidate for such lead-free alternatives due to its strong ferroelectricity plus it undergoes a diffuse phase transition at $320{ }^{\circ} \mathrm{C}$ corresponding to its Curie

\footnotetext{
${ }^{a}$ Department of Energy Materials and Technology, General Research Institute for Nonferrous Metals, Beijing, China. E-mail: sunboy_69@163.com

${ }^{b}$ School of Nuclear Technology and Chemistry \& Biology, Hubei University of Science and Technology, Xianning, China

${ }^{c}$ State Key Laboratory of New Ceramics and Fine Processing, School of Materials Science and Engineering, Tsinghua University, Beijing 100084, China

${ }^{d}$ College of Materials Science and Engineering, South China University of Technology, Guangzhou 510640, China

$\dagger$ These authors contributed equally to this work.
}

temperature. ${ }^{4}$ Thus, it was supposed that high energy-storage performance could be realized in NBT-based materials. Nevertheless, it is difficult to obtain desired electrical properties for pure NBT because of its high coercive field and conductivity. Moreover, because a large portion of energy is lost during phase transformation and domain wall motion, it is hard to obtain a high energy storage density for pure NBT.

Solid solutions of NBT with other perovskite-structured compounds have attracted much attention recently because of their greatly enhanced performances due to formation of rhombohedral (R) and tetragonal (T) morphotropic phase boundaries (MPB). ${ }^{5-9}$ Some efforts have been undertaken to enhance the energy-storage density of NBT-based films. For example, Li et al. obtained a high energy-storage density of about $13.02 \mathrm{~J} \mathrm{~cm}^{-3}$ and a medium efficiency of about $44.81 \%$ in $0.9\left(\mathrm{Na}_{0.5} \mathrm{Bi}_{0.5}\right) \mathrm{TiO}_{3}-$ $0.1 \mathrm{PbTiO}_{3}$ thin films due to high electric-field endurance and enhanced polarizability; ${ }^{10} \mathrm{Xu}$ et al. obtained a large energy density of about $36.1 \mathrm{~J} \mathrm{~cm}^{-3}$ and a corresponding efficiency of about $40.8 \%$ in $0.95\left(\mathrm{Na}_{0.5} \mathrm{Bi}_{0.5}\right) \mathrm{TiO}_{3}-0.05 \mathrm{SrTiO}_{3}$ thick films. ${ }^{11}$ In addition, some research progress has been made in the energy-storage field, especially in the active organic energy storage field. ${ }^{\mathbf{1 2 - 1 5}}$ For 
example, Chi et al. achieved a considerable energy storage density of $7.86 \mathrm{~J} \mathrm{~cm}^{-3}$ and a much greater $\eta$ of $58 \%$ at $310 \mathrm{kV} \mathrm{mm}^{-1}$ with a 3 vol\% $0.5 \mathrm{Ba}\left(\mathrm{Zr}_{0.2} \mathrm{Ti}_{0.8}\right) \mathrm{O}_{3}-0.5\left(\mathrm{Ba}_{0.7} \mathrm{Ca}_{0.3}\right) \mathrm{TiO}_{3}$ nanofibers (NFs)/ PVDF nanocomposite. ${ }^{14}\left(\mathrm{Na}_{0.5} \mathrm{Bi}_{0.5}\right) \mathrm{TiO}_{3}$-modified $\mathrm{K}_{0.5} \mathrm{Bi}_{0.5} \mathrm{TiO}_{3}$ (KBT), namely $(1-x)\left(\mathrm{Na}_{0.5} \mathrm{Bi}_{0.5}\right) \mathrm{TiO}_{3}-x\left(\mathrm{~K}_{0.5} \mathrm{Bi}_{0.5}\right) \mathrm{TiO}_{3}$, was found to exhibit improved dielectric and piezoelectric properties at the morphotropic phase boundary (MPB) region $(x=0.15)$ recently. ${ }^{16-21}$ Our previous research obtained a ferroelectric (remnant polarization $P_{\mathrm{r}}$ of $13.6 \mu \mathrm{C} \mathrm{cm}^{-2}$, maximum polarization $P_{\max }$ of $41.2 \mu \mathrm{C} \mathrm{cm}^{-2}$ ) and piezoelectric (effective piezoelectric coefficient $d_{33}^{*}$ of $56 \mathrm{pm} \mathrm{V}^{-1}$ ) properties in polycrystalline $0.85\left(\mathrm{Na}_{0.5} \mathrm{Bi}_{0.5}\right) \mathrm{TiO}_{3}-0.15\left(\mathrm{~K}_{0.5} \mathrm{Bi}_{0.5}\right) \mathrm{TiO}_{3}$ (NKBT) thin films. ${ }^{17}$ Moreover, it was reported that substitution of an A-site can obtain a relatively higher saturated polarization and/or lower remnant polarization, both of which are beneficial for improving its energy-storage density. Jeon et al. prepared a Mg-doped NBT-KBT thin film with ferroelectric $\left(P_{\mathrm{r}}=12 \mu \mathrm{C} \mathrm{cm}^{-2}, P_{\max }=52 \mu \mathrm{C} \mathrm{cm}^{-2}\right)$ and piezoelectric $\left(d_{33}^{*}=75 \mathrm{pm} \mathrm{V}^{-1}\right)$ properties by chemical solution deposition. ${ }^{22}$ According to our research, with an appropriate concentration Sc substitution in a NKBT film, a ferroelectric property $\left(P_{\mathrm{r}}=18.6 \mu \mathrm{C} \mathrm{cm}^{-2}, P_{\max }=57.4 \mu \mathrm{C} \mathrm{cm}^{-2}\right)$ and piezoelectric property $\left(d_{33}^{*}=67 \mathrm{pm} \mathrm{V}^{-1}\right)$ were obtained. ${ }^{23}$

Electrical properties of a ferroelectric thin film depend heavily on its structural properties, in which orientation of crystalline phase and film-substrate interfacial structure are important factors that need to be considered. It was reported that by introducing a buffer layer, a highly oriented crystallized perovskite thin film can be obtained, which was expected to perform with electrical properties better than those of polycrystalline thin films. For example, Xie et al. reported that a highly (100)-oriented $0.4 \mathrm{Bi}\left(\mathrm{Ni}_{0.5} \mathrm{Zr}_{0.5}\right) \mathrm{O}_{3}-0.6 \mathrm{PbTiO}_{3}$ film was prepared through alternately introducing PbO layers, in which an increased back-switching behavior $\left(P_{\max }-P_{\mathrm{r}}\right)$ process and decreased coercive field $\left(E_{\mathrm{c}}\right)$ were obtained; ${ }^{24} \mathrm{Chi}$ et al. obtained a greatly improved polarization performance $\left(P_{\mathrm{r}}=14.6 \mu \mathrm{C} \mathrm{cm}^{-2}\right.$, $P_{\max }=74.2 \mu \mathrm{C} \mathrm{cm}^{-2}$ ) in high-quality (100)-orientated NKBT thin film by using a $\mathrm{LaNiO}_{3}$ layer. ${ }^{25}$

Li et al. found that a $\mathrm{TiO}_{2}$ layer could induce highly preferred orientation in $\mathrm{Bi}_{3.15} \mathrm{Nd}_{0.85} \mathrm{Ti}_{3} \mathrm{O}_{12}$ and improved dielectric and ferroelectric performances. ${ }^{26}$ Aoki et al. reported that a thin $\mathrm{TiO}_{2}$ layer could lower the crystallization temperature of a PZT thin film and modified its properties. ${ }^{27}$ Therefore, it can be predicated that a possibility of enhancing energy-storage performance can be obtained by deliberately engineering $\mathrm{TiO}_{2}$ layers. The aim of this work was to explore the possibility of enhancing energy storage density in Sc-doped NKBT $\left[\left(\mathrm{Na}_{0.85} \mathrm{~K}_{0.15}\right)_{0.5^{-}}\right.$ $\mathrm{Bi}_{0.5} \mathrm{Ti}_{0.75} \mathrm{Sc}_{0.25} \mathrm{O}_{3}$ (NKBT-Sc)] films by deliberately engineering $\mathrm{TiO}_{2}$ layer effects. Dielectric, ferroelectric, and corresponding energy storage properties of $\mathrm{TiO}_{2}$-coated films were systematically investigated in an operating temperature range from $-150^{\circ} \mathrm{C}$ to $150^{\circ} \mathrm{C}$ and a frequency range from $100 \mathrm{~Hz}$ to $6 \mathrm{kHz}$.

\section{Experimental procedure}

\subsection{Material synthesis}

The NKBT-Sc films film-capacitors were prepared by aqueous sol-gel processing. As for the NKBT films, bismuth nitrate
$\left[\mathrm{Bi}\left(\mathrm{NO}_{3}\right)_{3} \cdot 5 \mathrm{H}_{2} \mathrm{O}\right]$, tetrabutyl titanate $\left[\mathrm{Ti}\left(\mathrm{OC}_{4} \mathrm{H}_{9}\right)_{4}\right]$, sodium acetate $\left[\mathrm{NaCOOCH}_{3}\right]$, potassium acetate $\left[\mathrm{KCOOCH}_{3}\right]$, and scandium acetate $\left[\mathrm{Sc}\left(\mathrm{COOCH}_{3}\right)_{3}\right]$ were used as precursor materials with glacial acetic acid, isopropyl alcohol, and distilled water as the solvents. First, $\mathrm{Ti}\left(\mathrm{OC}_{4} \mathrm{H}_{9}\right)_{4}$, isopropyl alcohol, and acetylacetone with a weight ratio of $1: 3: 3$ were mixed. Subsequently, glacial acetic acid in a $3: 1$ volume ratio was poured into the mixture. Then, $\mathrm{Bi}(\mathrm{NO})_{3}$, with an amount according to the composition of $\left(\mathrm{Na}_{0.85} \mathrm{~K}_{0.15}\right)_{0.5^{-}}$ $\mathrm{Bi}_{0.5} \mathrm{Ti}_{0.75} \mathrm{Sc}_{0.25} \mathrm{O}_{3}$, was dissolved in the solution, and in the meantime distilled water of the same volume as the glacial acid was added. Finally, $\mathrm{NaCOOCH}_{3}$ and $\mathrm{KCOOCH}_{3}$ and $\mathrm{Sc}\left(\mathrm{COOCH}_{3}\right)_{3}$ according to the $\left(\mathrm{Na}_{0.85} \mathrm{~K}_{0.15}\right)_{0.5} \mathrm{Bi}_{0.5} \mathrm{Ti}_{0.75} \mathrm{Sc}_{0.25} \mathrm{O}_{3}$ composition, were dissolved into the solution one by one. To prevent the appearance of cracks during aging and drying steps, an appropriate formamide (about $10: 1$ in volume ratio) was added to the above solution as a stabilizing agent. ${ }^{5}$ During the whole preparation process, the mixture was stirred constantly at room temperature until a transparent and stable yellow solution with a concentration of $0.26 \mathrm{M}$, determined by an inductive coupled plasma emission spectrometer (ICP), was obtained. In the preparation, ten percent excess of bismuth and twenty percent excess of sodium/potassium was added to balance out their volatility during the heat treatment process. The resultant solution was aged for about ten days before deposition. The organic solution for the $\mathrm{TiO}_{2}$ layer was prepared by dissolving tetrabutyl titanate $\left[\mathrm{Ti}\left(\mathrm{OC}_{4} \mathrm{H}_{9}\right)_{4}\right]$ into the solvent with mixed glacial acetic acid and isopropyl alcohol (weight ratio of $1: 1$ ) under constant stirring. Then, an appropriate formamide (about $10: 1$ in volume ratio) was added to the above solution forming a stable precursor sol. The resultant solution, with a concentration of $0.02 \mathrm{M}$ determined by ICP, was aged for about ten days before deposition.

The Ti-containing solution was spin-coated deposited on Pt/ $\mathrm{Ti} / \mathrm{SiO}_{2} / \mathrm{Si}$ followed by sequentially drying at $100{ }^{\circ} \mathrm{C}$ for $10 \mathrm{~min}$ and pyrolyzing at $400{ }^{\circ} \mathrm{C}$ for $5 \mathrm{~min}$, forming a thin $\mathrm{TiO}_{2}$ layer. Fig. 1 shows the XRD pattern of the crystallized $\mathrm{TiO}_{2}$ layer on the substrate. The peak at about $2 \theta=48^{\circ}$ corresponds to the (200) orientation of anatase phase $\mathrm{TiO}_{2}$. (JCPDS [Joint Committee on Powder Diffraction Standards] 89-4921). The inset shows the SEM surface morphology of the crystallized $\mathrm{TiO}_{2}$ layer, in which

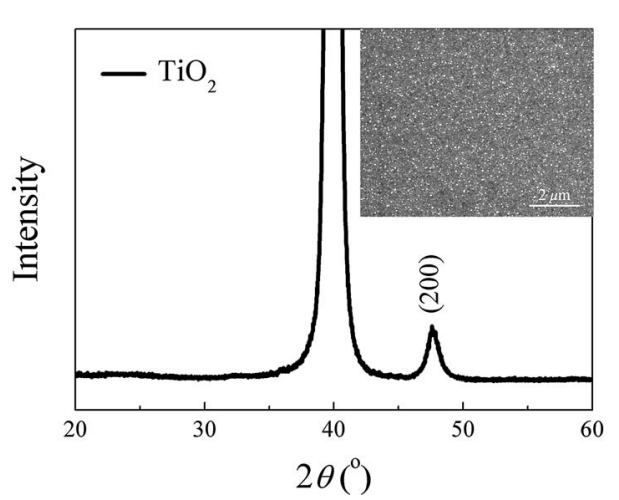

Fig. 1 XRD pattern of the $\mathrm{TiO}_{2}$ layer on $\mathrm{Pt} / \mathrm{Ti} / \mathrm{SiO}_{2} / \mathrm{S}$. The inset shows SEM surface morphology of the $\mathrm{TiO}_{2}$ layer on $\mathrm{Pt} / \mathrm{Ti} / \mathrm{SiO}_{2} / \mathrm{Si}$. 
isolated fine nanocrystals are sparsely distributed on the $\mathrm{Pt}$ electrode. Then, a NKBT-Sc layer was deposited on the $\mathrm{TiO}_{2}$ coated substrate by spin coating at $4500 \mathrm{rpm}$ for $30 \mathrm{~s}$, followed by drying at $100{ }^{\circ} \mathrm{C}$ for $10 \mathrm{~min}$ and pyrolyzing at $450{ }^{\circ} \mathrm{C}$ for 5 min. After three NKBT-Sc layers were deposited, then another $\mathrm{TiO}_{2}$ seeding layer was deposited onto the as-prepared NKBT-Sc film; i.e., the films were prepared by depositing one $\mathrm{TiO}_{2}$ layer and three NKBT-Sc layers alternately, forming a sandwich multilayer structured film. This processing was repeated for various times to obtain different thicknesses. For comparison, the NKBT-Sc film with one $\mathrm{TiO}_{2}$ layer inserted at the film-electrode interface and one without the $\mathrm{TiO}_{2}$ layer were also prepared. Finally, all the film samples were annealed at $700{ }^{\circ} \mathrm{C}$ for $5 \mathrm{~min}$ in a rapid thermal processing furnace. For characterizing the electric properties, top electrodes of platinum with a diameter of $0.2 \mathrm{~mm}$ were sputter-deposited onto the surface of the films. For ease of description, the NKBT-Sc film without a $\mathrm{TiO}_{2}$ layer, the NKBT-Sc film with a $\mathrm{TiO}_{2}$ seeding layer only at the film-electrode interface, and the film with alternate $\mathrm{TiO}_{2}$ seeding layers are denoted as NKBT-Sc-a, NKBT-Sc-b, and NKBT-Sc-c, respectively. A schematic drawing of the three kinds of structured films is shown in Fig. 2.

\subsection{Material characterization}

The phase composition of the prepared films was characterized by $\theta-2 \theta$ scan X-ray diffraction (XRD, D/max-RB, Rigaku, Tokyo, Japan) with CuK $\alpha$ radiation. Surface microstructure of the films was observed by field-emission scanning electron microscopy (FE-SEM, Hitachi-S4800, Hitachi, Japan). The ferroelectric hysteresis loops and dielectric properties were measured by a ferroelectric test module (TF 2000 analyzer, axiACCT, Aachen, Germany) and a precision impedance analyzer (4294A, Agilent, USA), respectively. Temperature was controlled by a temperature control stage (THMS600, Guildford, UK.).

\section{Results and discussion}

\subsection{Crystallographic orientation and microstructure}

Fig. 3 shows XRD patterns of NKBT-Sc-a, NKBT-Sc-b, and NKBTSc-c with the NKBT-Sc thicknesses of about 460 and $860 \mathrm{~nm}$, respectively. All the films grow in a pure-phase perovskite structure with no detectable impurity or other phases. The NKBT-Sc-a films are all randomly oriented with the (110) diffraction peak showing the highest intensity, and which is independent of film thickness. With the insertion of a $\mathrm{TiO}_{2}$ layer, the NKBT-Sc-b and NKBT-Sc-c films are (100) oriented, and in the meantime, the full width at half maximum (FWHM) of the (100) diffraction peak decreases, indicating a rise of crystallization degree. Because of close "in-plane" lattice parameters $(0.352 \mathrm{~nm})$ of anatase $\mathrm{TiO}_{2}$ with $a$-axis lattice parameters $(0.381 \mathrm{~nm})$ of $\mathrm{NKBT},{ }^{28-30} \mathrm{TiO}_{2}$ can provide nucleation sites to assist the (100)-oriented growth of the films, since lower interface energy promotes nucleation of grains. This can mostly be contributed to the formation of (100)-preferred orientation and better crystallinity of the films. As for the NKBTSc-b film, the degree of (100)-preferred orientation decreases

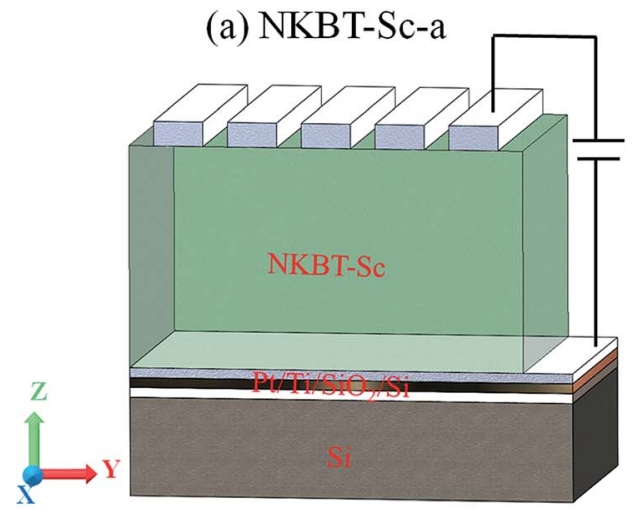

(b) NKBT-Sc-b

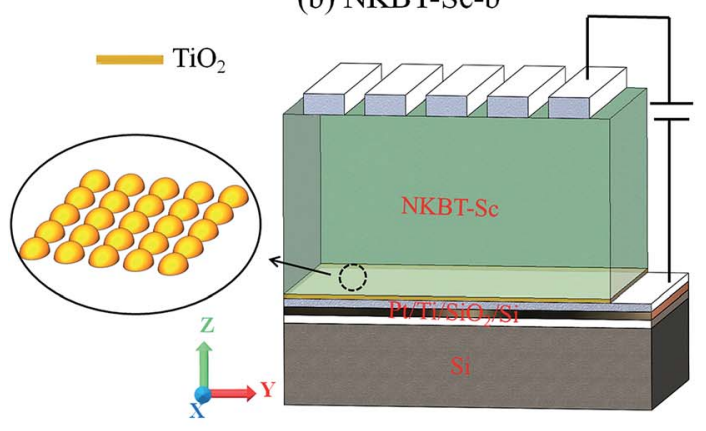

(c) NKBT-Sc-a

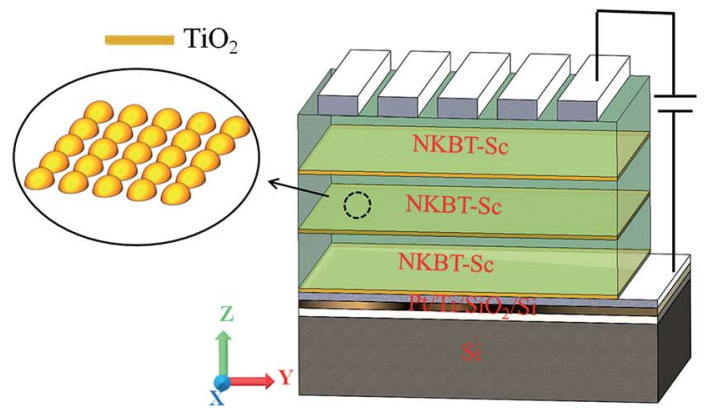

Fig. 2 Schematic drawing of the three kind of structured films: (a) NKBT-Sc-a, (b) NKBT-Sc-b, and (c) NKBT-Sc-c.

with increasing film thickness. When the $\mathrm{TiO}_{2}$ seeds are coated inside NKBT-Sc films, the obtained NKBT-Sc-c film exhibits a larger degree of (100)-preferred orientation than that of the NKBT-Sc-b films, and it does not decrease as the thickness increases. The $\mathrm{TiO}_{2}$ layer inserted at the film-electrode interface has a weaker effect on the upper part of the as-deposited NKBTSc film, which accordingly causes a lower degree of (100) orientation as the film thickness increases. Furthermore, $\mathrm{TiO}_{2}$ layers inserted inside the films can also act as seeds and play a role of nucleation, which further enhances (100)-preferred degree and facilitates the crystallization process. The degree of (100) orientation $\left(\mathrm{D}_{(100)}\right)$ is analyzed by calculating the peak integrated intensity ratio of (100) relative to the sum of (100), (110), and (111), ${ }^{31}$ and the results are given in Fig. 3. 

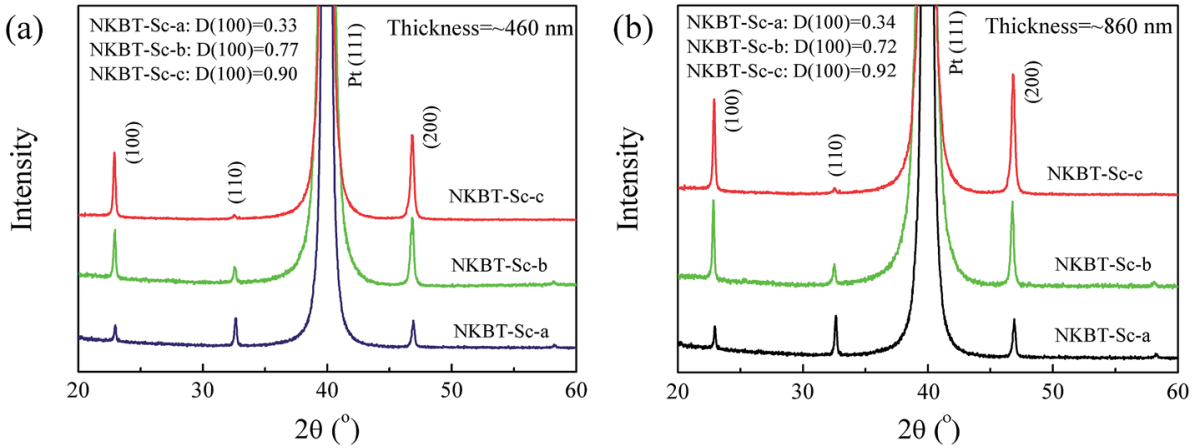

Fig. 3 XRD patterns of the three kinds of NKBT-Sc films with thicknesses of about (a) $460 \mathrm{~nm}$ and (b) $860 \mathrm{~nm}$.

Surface morphologies of the films are measured by FE-SEM. Fig. 4(a)-(c) show surface SEM images of the NKBT-Sc-a, NKBTSc-b, and NKBT-Sc-c films with about $860 \mathrm{~nm}$ thickness, respectively. These three kinds of NKBT-Sc films exhibit a dense morphology with uniform grain size distribution. Furthermore, the $\mathrm{TiO}_{2}$-coated NKBT-Sc films exhibit a larger mean grain size than the ones without a $\mathrm{TiO}_{2}$ layer. Transmission electron microscope (TEM, F20, Tecnai) was used to further study the microstructure and Fig. 4(d) shows the TEM image of the $860 \mathrm{~nm}$-thickness NKBT-Sc-c film at the region of the NKBT-Sc film- $\mathrm{TO}_{2}$ interface. Although there are some dislocations observed at the interface due to a slight lattice mismatch, a clear interface and, moreover, some consecutive lattice images at the interface are presented. In addition, according to the observation of the selected area electron diffraction (SAED) image, a highly preferred orientation exists in the NKBT-Sc film.

\subsection{Electrical properties and energy storage performance}

DC-applied field dependent dielectric constants $\left(\varepsilon_{\mathrm{r}}\right)$ and dissipation factors $(\tan \delta)$ of these three kinds of NKBT-Sc films were measured under a small oscillation signal at $1 \mathrm{kHz}$, as shown in Fig. 5(a). The butterfly shape of the dielectric constant DCapplied field curve confirms the ferroelectric characteristics of the three kinds of NKBT-Sc films. According to the testing data, the $\varepsilon_{\mathrm{r}}$ and $\tan \delta$ of these three kinds of films, with thicknesses of about $460 \mathrm{~nm}$ and $860 \mathrm{~nm}$ at 0 and $1200 \mathrm{kV} \mathrm{cm}^{-1}$, are listed in Table 1. Throughout the range of the DC bias field, the $\mathrm{TiO}_{2}{ }^{-}$
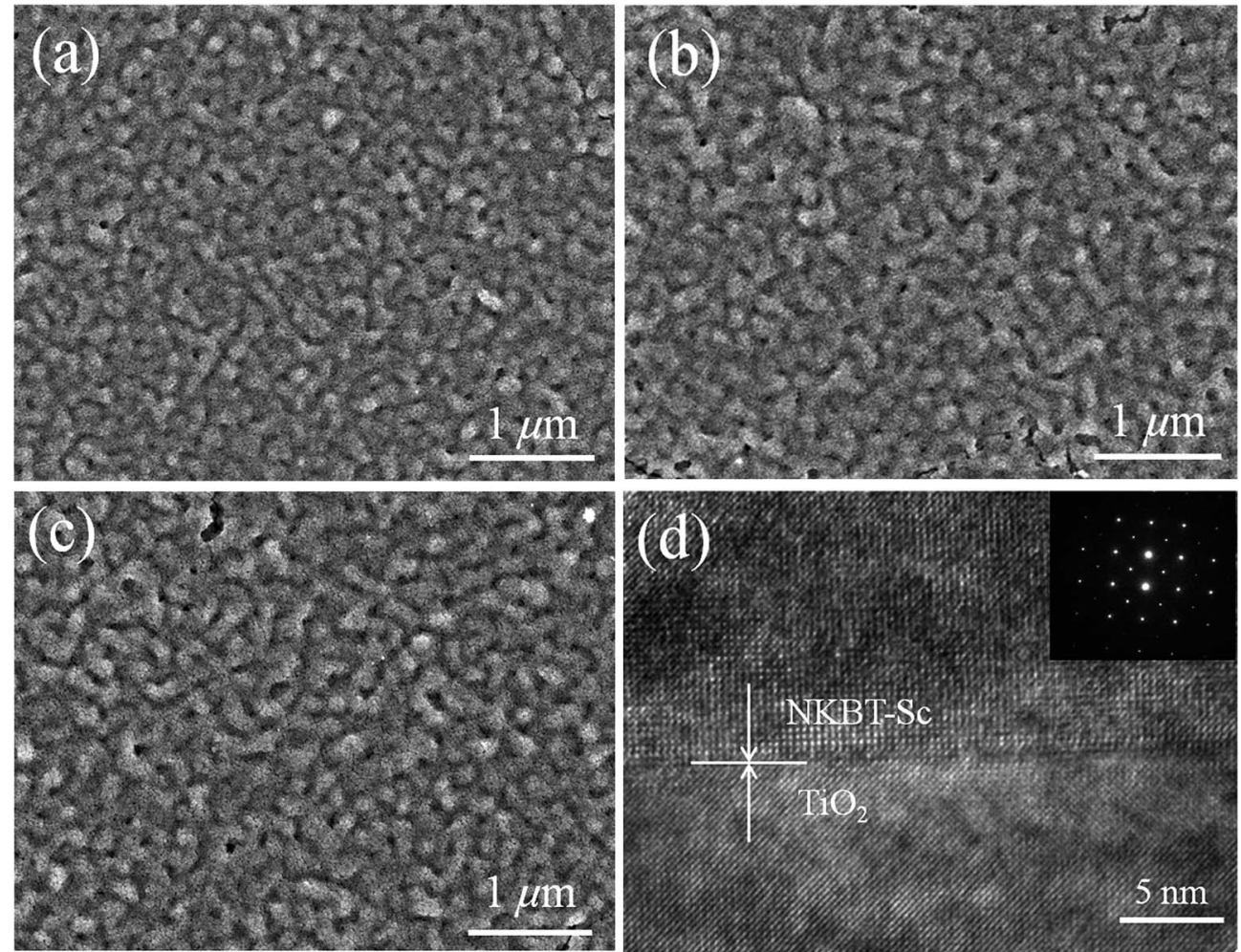

Fig. 4 SEM surface images of the (a) NKBT-Sc-a, (b) NKBT-Sc-b, and (c) NKBT-Sc-c films with thicknesses of about $860 \mathrm{~nm}$; (d) TEM image of the $860 \mathrm{~nm}$-thickness NKBT-Sc-c film. 

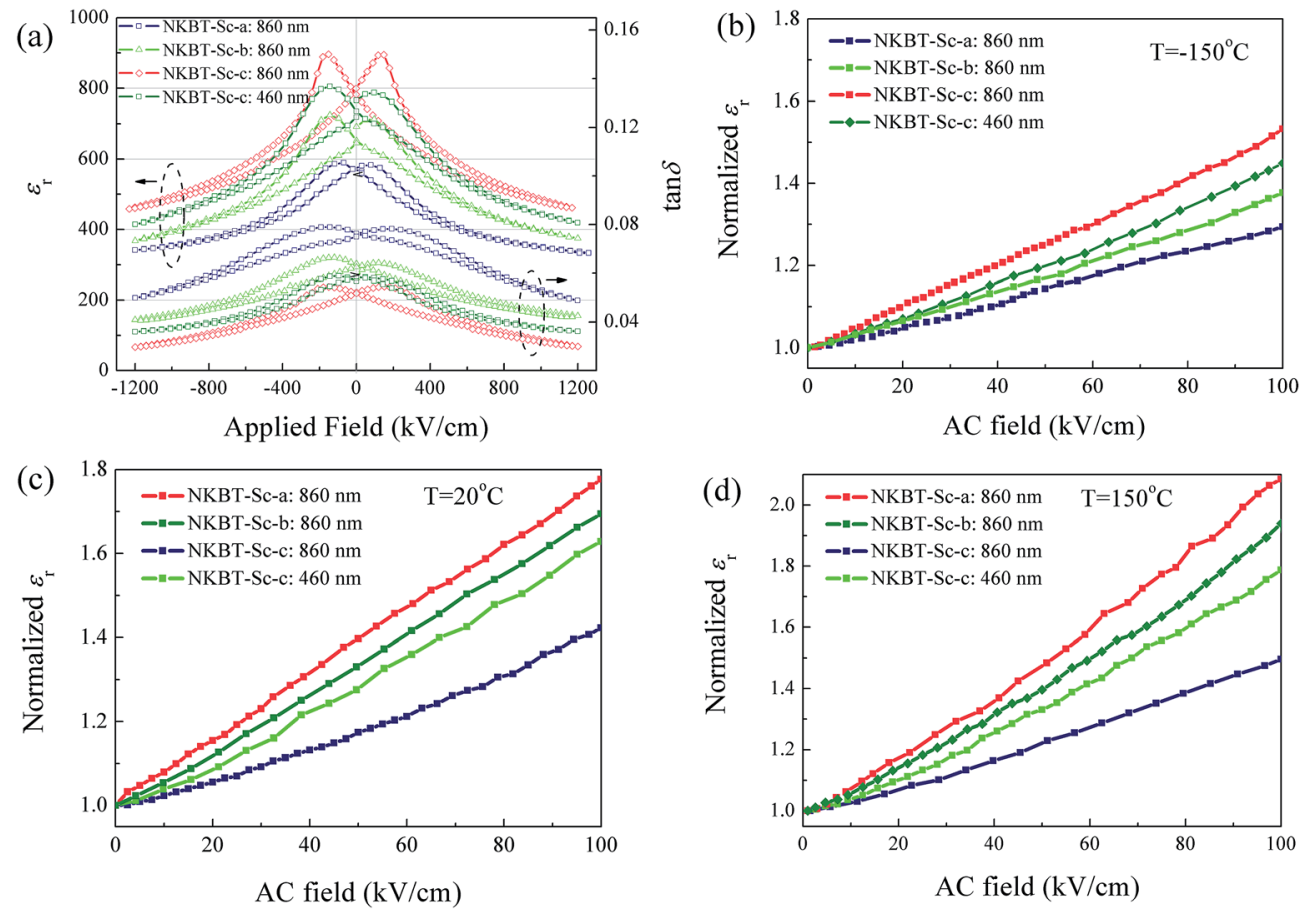

Fig. 5 (a) Applied voltage-dependent dielectric constant $\varepsilon_{\mathrm{r}}$ and dielectric loss tan $\delta$ of the three kinds of NKBT-SC films; AC field-dependent normalized dielectric constant measured at (b) $-150{ }^{\circ} \mathrm{C}$, (c) $20^{\circ} \mathrm{C}$, and (d) $150{ }^{\circ} \mathrm{C}$.

coated NKBT-Sc films show better dielectric properties than the film without a $\mathrm{TiO}_{2}$ layer. The $860 \mathrm{~nm}$-thickness NKBT-Sc-c film exhibits the largest $\varepsilon_{\mathrm{r}}$ of about 782 and lowest $\tan \delta$ of 0.051 , while the NKBT-Sc-a film with the same thickness exhibits the lowest $\varepsilon_{\mathrm{r}}$ of about 563 and largest $\tan \delta$ of about 0.077 . The improved dielectric properties for the NKBT-Sc-c and NKBT-Sc$\mathrm{b}$ films can be attributed to the following: first, $\mathrm{TiO}_{2}$ seeds ( $\mathrm{PbO}$ nanocrystals) on the surface of substrates and inside films can induce the high (100)-preferred orientation, which can improve domain-wall mobility. Second, the better crystallinity and consequently larger mean grain size in the highly (100)-oriented NKBT-Sc films can decrease the pinning-effect of the defects. Besides, for any of these three structures, the $860 \mathrm{~nm}$-thickness film exhibits a better dielectric property than the $460 \mathrm{~nm}$ thickness film. The higher (100)-preferred orientation for the thicker NKBT-Sc-b film, and better crystallinity for the thicker

Table 1 The $\varepsilon_{r}$ and $\tan \delta$ of the three kinds of NKBT-Sc films with thicknesses of about $460 \mathrm{~nm}$ and $860 \mathrm{~nm}$ at DC applied fields of 0 and $1200 \mathrm{kV} \mathrm{cm}^{-1}$

\begin{tabular}{|c|c|c|c|c|c|c|}
\hline \multirow[b]{2}{*}{ Sample } & \multicolumn{2}{|c|}{ NKBT-Sc-a } & \multicolumn{2}{|c|}{ NKBT-Sc-b } & \multicolumn{2}{|c|}{ NKBT-Sc-c } \\
\hline & $460 \mathrm{~nm}$ & $860 \mathrm{~nm}$ & $460 \mathrm{~nm}$ & $860 \mathrm{~nm}$ & $460 \mathrm{~nm}$ & $860 \mathrm{~nm}$ \\
\hline \multicolumn{7}{|c|}{$0 \mathrm{kV} \mathrm{cm}^{-1}$} \\
\hline$\varepsilon_{\mathrm{r}}$ & 487 & 563 & 617 & 687 & 725 & 782 \\
\hline $\tan \delta$ & 0.079 & 0.077 & 0.068 & 0.063 & 0.058 & 0.051 \\
\hline \multicolumn{7}{|c|}{$1200 \mathrm{kV} \mathrm{cm}{ }^{-1}$} \\
\hline$\varepsilon_{\mathrm{r}}$ & 307 & 343 & 342 & 387 & 418 & 463 \\
\hline $\tan \delta$ & 0.053 & 0.047 & 0.043 & 0.041 & 0.038 & 0.034 \\
\hline
\end{tabular}

NKBT-Sc-a and NKBT-Sc-c can be considered as the main reasons to cause the enhanced dielectric response. In addition, it is observed that differences of the $\varepsilon_{\mathrm{r}}$ value gradually decrease with increasing DC applied field and tend to become insignificant among these films at a high DC-applied field. It is well known that the dielectric response includes intrinsic contributions and extrinsic contributions. DC-applied field-dependent dielectric properties come from combined contributions of field-dependent intrinsic dielectric permittivity and extrinsic dielectric permittivity. At high DC-applied fields, extrinsic contributions, which mainly originate from domain wall motion, tend to be pinned, thus dielectric response mostly arises from intrinsic contributions of the film. This indicates that the improved dielectric constant after the insertion of a $\mathrm{TiO}_{2}$ layer at zero DC applied field is mainly attributed to an extrinsic contribution, i.e., motion of domain walls. By inserting a $\mathrm{TiO}_{2}$ seed layer at the film-electrode interface and inside films, the high (100) orientation and better crystallinity can depress the pinning-effect of the charged defects and thus enhance domain-wall mobility. This may be the main reason causing the enhanced dielectric properties of the NKBT-Sc$\mathrm{b}$ and NKBT-Sc-c films. In addition, lowered dielectric loss in the $\mathrm{TiO}_{2}$-coated NKBT-Sc films compared with the NKBT-Sca film can be attributed to the rise of crystallization degree. Since the pinning-effect of the defects will weaken gradually with increasing AC field, more domain walls contribute to the dielectric permittivity at larger AC fields, which can be characterized by the Rayleigh relation. Fig. 5(b)-(d) show the AC fielddependent amplitude of the normalized dielectric constant, measured at $-150{ }^{\circ} \mathrm{C}, 20{ }^{\circ} \mathrm{C}$, and $150{ }^{\circ} \mathrm{C}$, respectively. The 
dielectric constants increase linearly with increasing AC field, conforming to the Rayleigh relation. ${ }^{32}$ The Rayleigh coefficient, which is calculated according to the slope of the curves, is used to represent the contribution from a pinned domain wall and a larger Rayleigh coefficient means more contribution from domain walls in the films. The NKBT-Sc-b and NKBT-Sc-c films exhibit a larger Rayleigh coefficient than the NKBT-Sc-a film, meaning more domain walls contribute to the dielectric response at a large AC field. Higher domain wall mobility can be ascribed to better crystallization quality and a higher degree of (100)-preferred orientation. When measuring at a temperature range from $20{ }^{\circ} \mathrm{C}$ to $-150{ }^{\circ} \mathrm{C}$, the dielectric constant decreases gradually, and in the meantime the dielectric constant differences between the three kinds of films become smaller. Because the motion of a pinned domain wall is a thermally activated process, which will gradually diminish as the measurement temperature decreases, fewer domain walls contribute to the dielectric response at low measurement temperatures.

The dielectric constants of these three kinds of $860 \mathrm{~nm}$ thickness NKBT-Sc film were also measured at a frequency range of $100 \mathrm{~Hz}$ to $6 \mathrm{kHz}$, as shown in Fig. 6(a), and the corresponding applied field-dependent dielectric constants of the $860 \mathrm{~nm}$-thickness NKBT-Sc-c film measured at different frequencies are shown in Fig. 6(b). When measuring at a frequency from $100 \mathrm{~Hz}$ to $6 \mathrm{kHz}$, the $\varepsilon_{\mathrm{r}}$ values of the NKBT-Sc$\mathrm{b}$ and NKBT-Sc-c films decline slightly, while those values of the NKBT-Sc-a film were found to decrease more obviously. This indicates that the $\mathrm{TiO}_{2}$-coated NKBT-Sc films are less frequency sensitive than those without a $\mathrm{TiO}_{2}$ layer under the same measurement conditions.

For studying ferroelectric properties, polarization-applied field hysteresis loops with sequentially increasing applied fields were measured for these three kinds of NKBT-Sc films at $1 \mathrm{kHz}$. The applied field dependent hysteresis loops of the three kinds of NKBT-Sc films with thicknesses of about $860 \mathrm{~nm}$ and $460 \mathrm{~nm}$ measured at room temperature are shown in Fig. 7(a) and (b), respectively. All the films exhibit slim $P-E$ loops at high electric-fields, meaning a high electric-field endurance. The insertion of a $\mathrm{TiO}_{2}$ layer exerts a positive impact on the $P_{\max }$ value but nearly no effect on the $P_{\mathrm{r}}$ of these films. This can be attributed to the $\mathrm{TiO}_{2}$ layer effect by motivating more domain response to and orienting along the external field direction. Besides, a larger spontaneous polarization exists along the (100) orientation than that along the (110) orientation. Thus, with the insertion of $\mathrm{a} \mathrm{TiO}_{2}$ layer, the highly (100)-oriented NKBT-Sc film exhibits a higher ferroelectric response than the polycrystalline one. Grain boundaries and interfacial defects are generally considered as a potent leakage current path. The larger mean grain size in the $\mathrm{TiO}_{2}$-coated films results in a decreased current path, which lowers density of charged defects gathered at the NKBT-Sc film- $\mathrm{TiO}_{2}$ interfaces and thus causes reduction of the pinning-effect of the charged defects. However, once the applied field is removed, those polar domains tend to switch to their original random polarized state, and this increases a backswitching behavior $\left(P_{\max }-P_{\mathrm{r}}\right)$ process. Energy storage density $W\left(W=\int_{P_{\mathrm{r}}}^{P_{\max }} E \mathrm{~d} P\right)$, energy loss $W_{\text {loss }}$ and energy efficiency $\eta$ $\left(\eta=W /\left(W+W_{\text {loss }}\right)\right)$ in dielectric capacitors can be calculated from the $P-E$ loops. ${ }^{33,34}$ Ferroelectric materials with higher dielectric breakdown strength (BDS) and larger differences between $P_{\max }$ and $P_{\mathrm{r}}$ have the potential to be applied in electronic devices and systems such as high energy-storage capacitors. Fig. 7(c) depicts the applied field dependent energy density and efficiency of these three kinds of NKBT-Sc films. According to the calculated results, the energy density $W$ and energy efficiency $\eta$ of these three kinds of films, with thicknesses of about $460 \mathrm{~nm}$ and $860 \mathrm{~nm}$ at $1200 \mathrm{kV} \mathrm{cm}^{-1}$, are listed in Table 2. The $P-E$ loops of the $860 \mathrm{~nm}$-thickness NKBT-Sc-c film measured at room temperature under different electric fields are shown in Fig. 7(d). The energy storage density $W$ of these three kinds of NKBT-Sc films are found to increase almost linearly with increasing applied field, while in the meantime the energy efficiency $\eta$ shows an opposite tendency. The $\mathrm{TiO}_{2}$ layer has a strong impact on energy-storage performance and moreover this performance greatly enlarges by deliberately engineering a strong $\mathrm{TiO}_{2}$ layer. The $860 \mathrm{~nm}$-thickness NKBT-Sc-c film exhibits the best energy-storage performance among the three kinds of NKBT films with a $W$ value of about $22.7 \mathrm{~J} \mathrm{~cm}^{-3}$ and an efficiency $\eta$ of about 51.5\%, while the $860 \mathrm{~nm}$-thickness NKBT-Sc-a film showed a $W$ value of about $12.3 \mathrm{~J} \mathrm{~cm}^{-3}$ and $\eta$ value of about $43.7 \%$ at $1200 \mathrm{kV} \mathrm{cm}^{-1}$. In addition, the thicker
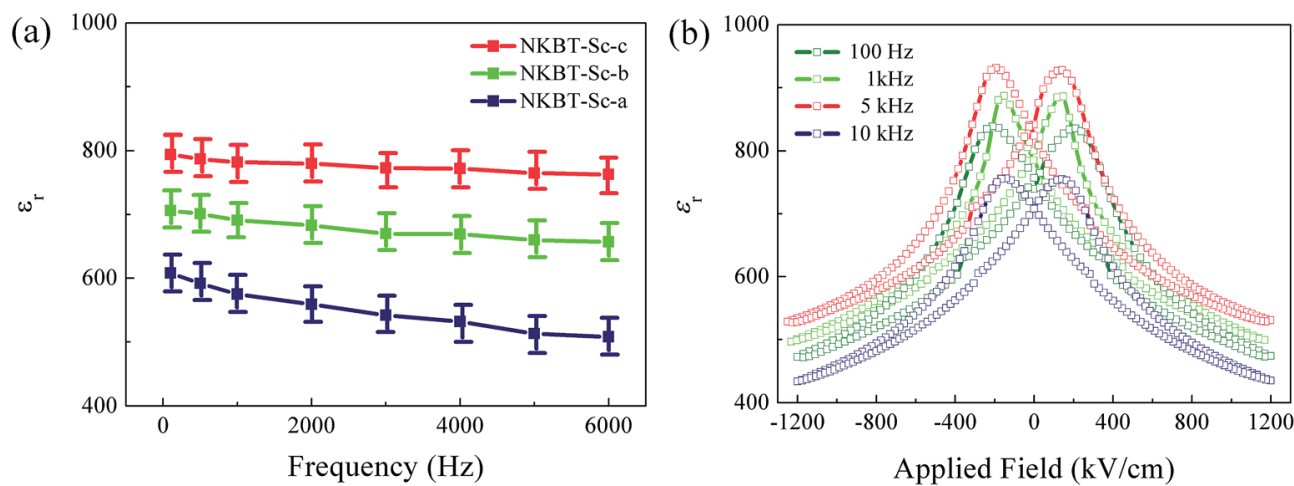

Fig. 6 (a) Dielectric constants of these three kinds of $860 \mathrm{~nm}$-thickness NKBT-Sc films measured at a frequency range of $100 \mathrm{~Hz}$ to $6 \mathrm{kHz}$. (b) Corresponding applied field-dependent dielectric constants of the $860 \mathrm{~nm}$-thickness NKBT-Sc-c film measured at different frequencies. 

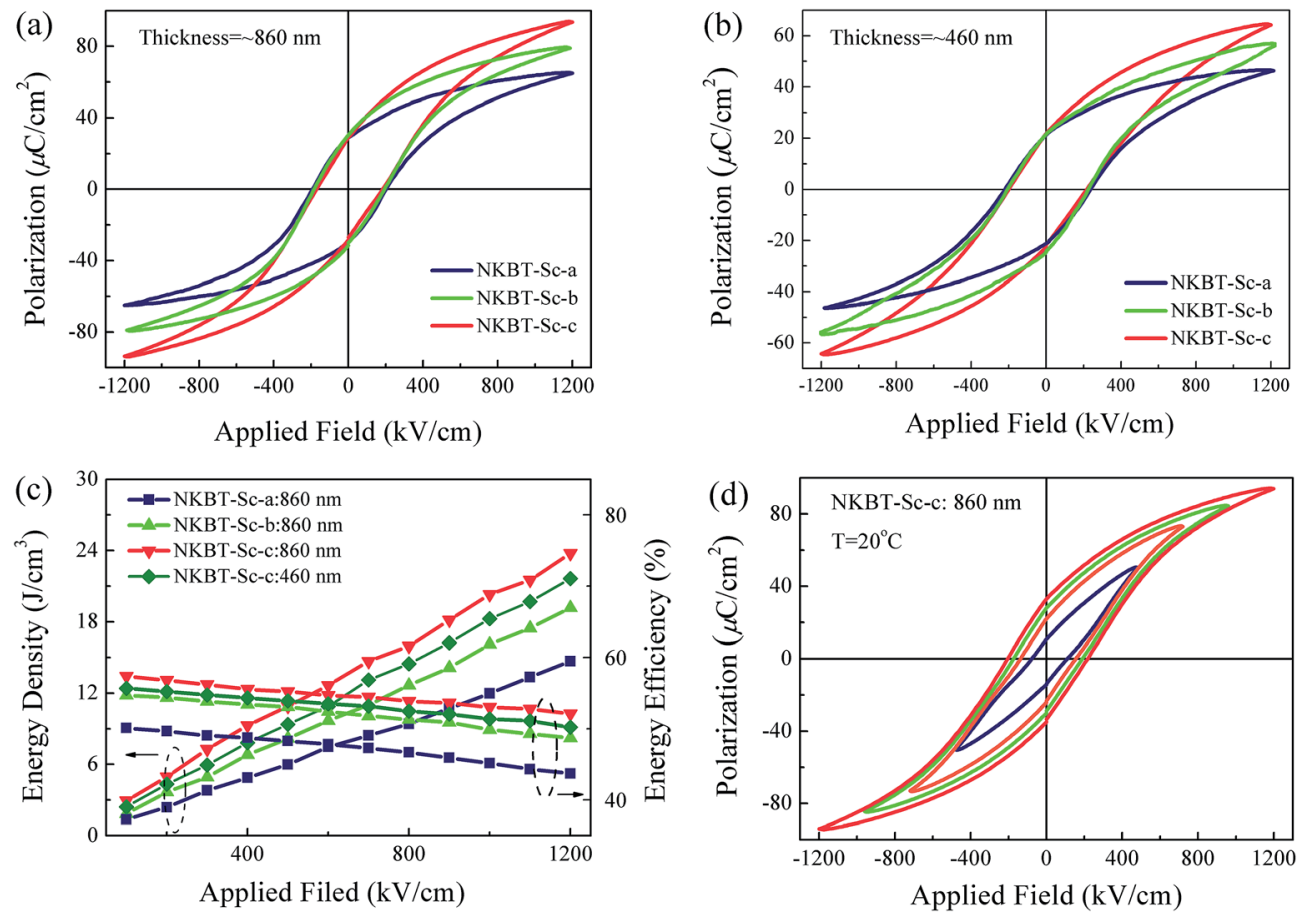

Fig. 7 (a) Applied field-dependent hysteresis loops of the three kinds of NKBT-Sc films measured at room temperature with thicknesses of about (a) $860 \mathrm{~nm}$ and (b) $460 \mathrm{~nm}$. (c) Applied field dependent energy density and efficiency of the three kinds of NKBT-Sc films. (d) Applied fielddependent hysteresis loops of the $860 \mathrm{~nm}$-thickness NKBT-Sc-c film measured at room temperature under different electric fields.

Table 2 The energy density $W$ and energy efficiency $\eta$ of the three kinds of NKBT-Sc films with thicknesses of about $460 \mathrm{~nm}$ and $860 \mathrm{~nm}$ at $1200 \mathrm{kV} \mathrm{cm}^{-1}$

\begin{tabular}{|c|c|c|c|c|c|c|}
\hline \multirow[b]{2}{*}{ Sample } & \multicolumn{2}{|c|}{ NKBT-Sc-a } & \multicolumn{2}{|c|}{ NKBT-Sc-b } & \multicolumn{2}{|c|}{ NKBT-Sc-c } \\
\hline & $460 \mathrm{~nm}$ & $860 \mathrm{~nm}$ & $460 \mathrm{~nm}$ & $860 \mathrm{~nm}$ & $460 \mathrm{~nm}$ & $860 \mathrm{~nm}$ \\
\hline$W\left(\mathrm{~J} \mathrm{~cm}^{-3}\right)$ & 10.8 & 12.3 & 16.2 & 18.4 & 20.5 & 22.7 \\
\hline$\eta$ & $41.2 \%$ & $43.7 \%$ & $47.3 \%$ & $48.7 \%$ & $50.6 \%$ & $51.5 \%$ \\
\hline
\end{tabular}

$\mathrm{TiO}_{2}$-coated NKBT-Sc films (860 $\mathrm{nm}$-thickness) exhibit a higher $W$ value together with a lower $\eta$ value than the $460 \mathrm{~nm}$-thickness ones. Energy density obtained at a low applied field in the $\mathrm{TiO}_{2}$ coated NKBT-Sc films in this work is superior to the values reported for NBT-based ceramics. ${ }^{35-37}$

As temperature stability of energy-storage performance is crucial for practical applications of capacitors, the temperature dependent energy storage performance of these three kinds of NKBT-Sc films was measured at a temperature range from -150 to $150{ }^{\circ} \mathrm{C}$ at $1200 \mathrm{kV} \mathrm{cm}^{-1}$, and the result is shown in Fig. 8(a). Fig. 8(b) shows the corresponding $P-E$ loops of the $860 \mathrm{~nm}-$ thickness NKBT-Sc-c film under different electric fields measured at $-150{ }^{\circ} \mathrm{C}$. With the insertion of a $\mathrm{TiO}_{2}$ layer, the NKBT-Sc-b and NKBT-Sc-c films display a slight fluctuation at this temperature range, which indicates that they are insensitive to the energy-storage properties used to measure temperature and therefore have a good temperature dependent stability with these $\mathrm{TiO}_{2}$-coated NKBT-Sc films under the measurement conditions. In comparison, for the NKBT-Sc-a film, the energystorage density shows some decline as the measurement temperature decreases from room temperature to $-150{ }^{\circ} \mathrm{C}$.

The polarization-applied field hysteresis loops of the $860 \mathrm{~nm}$-thickness NKBT-Sc-c film measured at a frequency range from $100 \mathrm{~Hz}$ to $6 \mathrm{kHz}$ is shown in Fig. 9. It is observed that both the $P_{\max }$ and $P_{\mathrm{r}}$ values slightly decrease with an increase of measurement frequency. According to these results, the inset depicts the frequency dependent energy density of the $860 \mathrm{~nm}$ thickness NKBT-Sc-c film. Because of the small variation of the $P_{\max }-P_{\mathrm{r}}$ values, the energy storage density $W$ slightly changes in a small range of about $21.6 \mathrm{~J} \mathrm{~cm}^{-3}$ and $23.2 \mathrm{~J} \mathrm{~cm}^{-3}$ in the measurement frequency range, indicating a good frequency dependent stability.

Low leakage current density is always essential for the application of ferroelectric materials in high performance storage devices. The applied field dependence with the leakage current density $(J)$ of the $860 \mathrm{~nm}$-thickness NKBT-Sc-c film was measured at a temperature range from $-150{ }^{\circ} \mathrm{C}$ to $150{ }^{\circ} \mathrm{C}$, and the results are shown in Fig. 10. It was observed that the $J$ value increased slightly as the measurement temperature increased from $-150{ }^{\circ} \mathrm{C}$ to $150{ }^{\circ} \mathrm{C}$, and did not break down under $1200 \mathrm{kV} \mathrm{cm}^{-1}$ at $150^{\circ} \mathrm{C}$. Furthermore, the $J$ value maintained a relatively low value throughout the measurement temperature range, which indicated that the NKBT-Sc-c film can work over a wide operating temperature. This low leakage current density can mainly be attributed to a reduction of charged defects at the NKBT-Sc film- $-\mathrm{TiO}_{2}$ interface and grain boundary density in the films. 

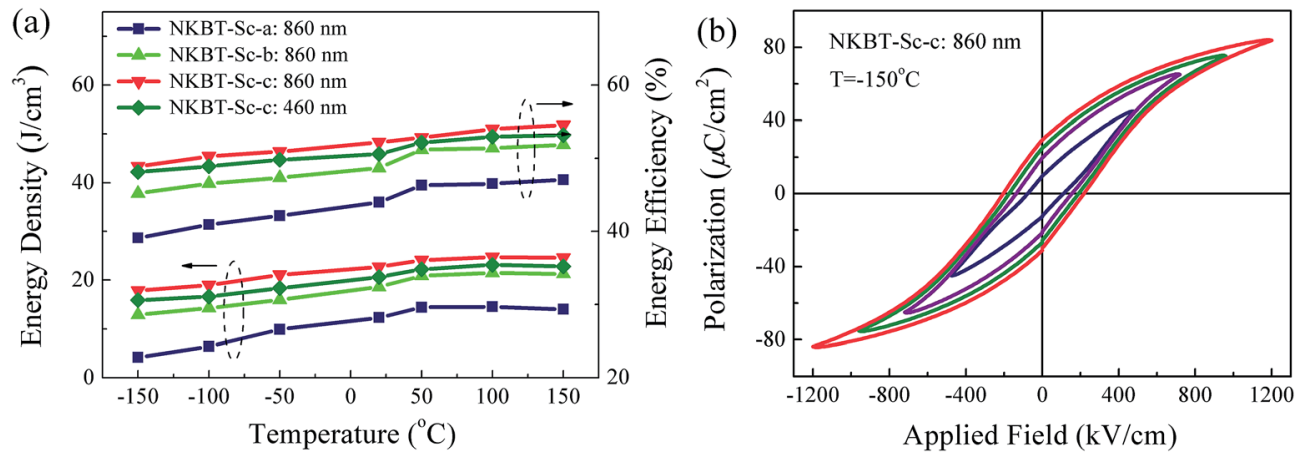

Fig. 8 (a) Temperature-dependent energy storage performances of the three kinds of NKBT-Sc films measured at a temperature range from -150 to $150^{\circ} \mathrm{C}$. (b) Applied field-dependent hysteresis loops of the $860 \mathrm{~nm}$-thickness NKBT-Sc-c film under different electric fields measured at $-150{ }^{\circ} \mathrm{C}$

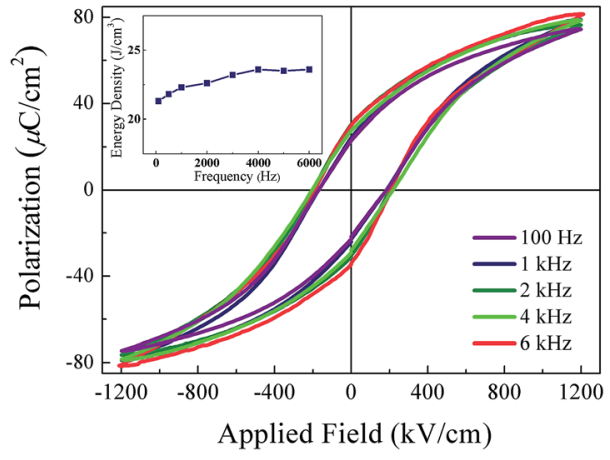

Fig. 9 Applied field dependent hysteresis loops of the three kinds of $860 \mathrm{~nm}$-thickness NKBT-Sc-c film measured at a frequency range of $100 \mathrm{~Hz}$ to $6 \mathrm{kHz}$. The inset shows frequency-dependent energy density of the $860 \mathrm{~nm}$-thickness NKBT-Sc-c film.

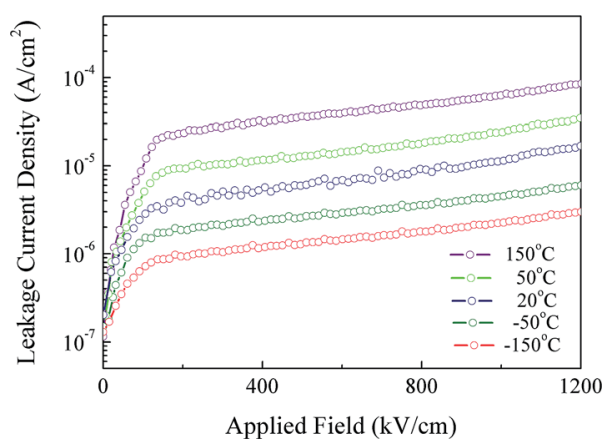

Fig. 10 Applied field-dependent leakage current density $\mathrm{J}$ of the 860 $\mathrm{nm}$-thickness NKBT-Sc-c film measured at a temperature range from -150 to $150{ }^{\circ} \mathrm{C}$.

\section{Conclusion}

The (100)-oriented NKBT-Sc films with thicknesses ranging from about 460 to $860 \mathrm{~nm}$ were fabricated by an aqueous sol-gel method on a platinized silicon substrate through alternately introducing $\mathrm{TiO}_{2}$ layers. Additionally, effects of $\mathrm{TiO}_{2}$ seeds on microstructure and electrical properties were investigated over a temperature range from $-150{ }^{\circ} \mathrm{C}$ to $150{ }^{\circ} \mathrm{C}$ and a frequency range from $100 \mathrm{~Hz}$ to $6 \mathrm{kHz}$. The $\mathrm{TiO}_{2}$ layer coated inside the films can greatly enhance the (100) texture degree, which did not decrease as the thickness increased, and moreover are beneficial for the crystallization process of the NKBT-Sc films. Compared with the NKBT-Sc films without $\mathrm{TiO}_{2}$ seeds, the $\mathrm{TiO}_{2}-$ coated NKBT-Sc films exhibit a great enhancement in electric properties as well as energy storage performance. Consequently, a high dielectric constant of about 782 and a low dielectric loss of about 0.051 at $1 \mathrm{kHz}$, together with an enhanced energy density of about $22.7 \mathrm{~J} \mathrm{~cm}^{-3}$ and efficiency of about $51.5 \%$, were achieved in the $860 \mathrm{~nm}$-thickness NKBT-Sc-c film at room temperature. Besides, the $\mathrm{TiO}_{2}$-coated NKBT-Sc films exhibit a greatly enhanced temperature dependent energy storage stability in a temperature range from $-150{ }^{\circ} \mathrm{C}$ to $150{ }^{\circ} \mathrm{C}$, together with a frequency dependent energy storage stability in the frequency range from $100 \mathrm{~Hz}$ to $6 \mathrm{kHz}$. This great enhancement in the dielectric response and energy storage performance can be attributed to higher domain walls motion by increasing crystallinity and (100)-preferred orientation in the films. In addition, the $J$ value of the $860 \mathrm{~nm}$-thickness NKBT-Scc film maintains a relatively low value throughout the measurement temperature range, which also means that it can work in a wide operating temperature range.

\section{Conflicts of interest}

There are no conflicts to declare.

\section{Acknowledgements}

The work was supported by the National Natural Science Foundation of China (Grant No. 51402020), the Natural Science Foundation of Hubei Province of China (Grant No. 2017CFB526), and the Educational Commission of Hubei Province of China (Grant No. D20172803).

\section{References}

$1 \mathrm{~K}$. Wasa, T. Matsushima and H. Adachi, Thin-film piezoelectric materials for a better energy harvesting MEMS, J. Microelectromech. Syst., 2012, 21, 451-457. 
2 D. L. Polla and L. F. Francis, Ferroelectric thin films in microelectromechanical systems applications, MRS Bull., 1996, 21, 59-65.

3 S. K. Dey and R. Zuleeg, Integrated sol-gel PZT thin-films on $\mathrm{Pt}, \mathrm{Si}$, and GaAs for non-volatile memory applications, Ferroelectrics, 1990, 108, 37-46.

4 S. Teranishi, M. Suzuki, Y. Noguchi, M. Miyayama, C. Moriyoshi, Y. Kuroiwa, K. Tawa and S. Mori, Giant strain in lead-free $\left(\mathrm{Bi}_{0.5} \mathrm{Na}_{0.5}\right) \mathrm{TiO}_{3}$-based single crystals, Appl. Phys. Lett., 2008, 92, 1829051-1829053.

5 M. Abazari, A. Safari, S. S. N. Bharadwaja and S. TrolierMcKinstry, Dielectric and piezoelectric properties of leadfree (Bi,Na)TiO ${ }_{3}$-based thin films, Appl. Phys. Lett., 2010, 96, 082903.

6 X. J. Zheng, J. Y. Liu, J. F. Peng, X. Liu, Y. Q. Gong, K. S. Zhou and D. H. Huang, Effect of potassium content on electrostrictive properties of $\mathrm{Na}_{0.5} \mathrm{Bi}_{0.5} \mathrm{TiO}_{3}$-based relaxor ferroelectric thin films with morphotropic phase boundary, Thin Solid Films, 2013, 548, 118-124.

7 F. Gao, X. Dong, C. Mao, W. Liu, H. Zhang, L. Yang, F. Cao, G. Wang and J. Jones, Energy-storage properties of $0.89 \mathrm{Bi}_{0.5} \mathrm{Na}_{0.5} \mathrm{TiO}_{3}-0.06 \mathrm{BaTiO}_{3}-0.05 \mathrm{~K}_{0.5} \mathrm{Na}_{0.5} \mathrm{NbO}_{3} \quad$ lead-free anti-ferroelectric ceramics, J. Am. Ceram. Soc., 2011, 94, 4382-4386.

8 K. Sakata, T. Takenaka and Y. Naitou, Phase relations, dielectric and piezoelectric properties of ceramics in the system $\left(\mathrm{Bi}_{0.5} \mathrm{Na}_{0.5}\right) \mathrm{TiO}_{3}-\mathrm{PbTiO}_{3}$, Ferroelectrics, 1992, 131, 219-226.

9 O. Elkechai, P. Marchet, P. Thomas and M. Manier, JeanPierre Mercurio, Structural and dielectric study of the $\mathrm{Na}_{0.5} \mathrm{Bi}_{0.5} \mathrm{TiO}_{3}-\mathrm{PbTiO}_{3}$ and $\mathrm{K}_{0.5} \mathrm{Bi}_{0.5} \mathrm{TiO}_{3}-\mathrm{PbTiO}_{3}$ systems, $J$. Mater. Chem., 1997, 7, 91-97.

10 P. Lia, J. W. Zhai, B. Shen, W. Li, H. R. Zeng and K. Y. Zhao, High recoverable energy storage density and large piezoelectric response in $\left(\mathrm{Bi}_{0.5} \mathrm{Na}_{0.5}\right) \mathrm{TiO}_{3}-\mathrm{PbTiO}_{3}$ thin films prepared by a sol-gel method, J. Eur. Ceram. Soc., 2017, 37, 3319-3327.

$11 \mathrm{Z}$. Xu, X. Hao and S. An, Dielectric properties and energystorage performance of $\left(\mathrm{Na}_{0.5} \mathrm{Bi}_{0.5}\right) \mathrm{TiO}_{3}-\mathrm{SrTiO}_{3}$ thick films derived from polyvinylpyrrolidone-modified chemical solution, J. Alloys Compd., 2015, 639, 387-392.

12 V. K. Prateek and R. K. Thakur, Gupta, Recent progress on ferroelectric polymer-based nanocomposites for high energy density capacitors: synthesis, dielectric properties, and future aspects, Chem. Rev., 2016, 116, 4260-4317.

13 Q. G. Chi, J. F. Dong, C. H. Zhang, C. P. Wong, X. Wang and Q. Q. Lei, Nano iron oxide-deposited calcium copper titanate/polyimide hybrid films induced by an external magnetic field: toward a high dielectric constant and suppressed loss, J. Mater. Chem. C, 2016, 4, 8179-8188.

14 Q. G. Chi, T. Ma, Y. Zhang, Y. Cui, C. H. Zhang, J. Q. Lin, X. Wang and Q. Q. Lei, Significantly enhanced energy storage density for poly(vinylidenefluoride) composites by induced PDA-coated $0.5 \mathrm{Ba}\left(\mathrm{Zr}_{0.2} \mathrm{Ti}_{0.8}\right) \mathrm{O}_{3}-0.5\left(\mathrm{Ba}_{0.7} \mathrm{Ca}_{0.3}\right) \mathrm{TiO}_{3}$ nanofibers, J. Mater. Chem. A, 2017, 5, 16757-16766.

15 Q. G. Chi, T. Ma, J. F. Dong, Y. Cui, Y. Zhang, C. H. Zhang, S. C. Xu, X. Wang and Q. Q. Lei, Enhanced thermal conductivity and dielectric properties of iron oxide/ polyethylene nanocomposites induced by a magnetic field, Sci. Rep., 2017, 7, 3072-3082.

16 T. Yu, K. W. Kwok and H. L. W. Chan, The synthesis of leadfree ferroelectric $\mathrm{Bi}_{0.5} \mathrm{Na}_{0.5} \mathrm{TiO}_{3}-\mathrm{Bi}_{0.5} \mathrm{~K}_{0.5} \mathrm{TiO}_{3}$ thin films by sol-gel method, Mater. Lett., 2007, 61, 2117-2120.

17 Y. Y. Wu, X. H. Wang, C. F. Zhong and L. T. Li, Effect of Na/K excess on the electrical properties of $\mathrm{Na}_{0.5} \mathrm{Bi}_{0.5} \mathrm{TiO}_{3}-$ $\mathrm{K}_{0.5} \mathrm{Bi}_{0.5} \mathrm{TiO}_{3}$ thin films prepared by sol-gel processing, Thin Solid Films, 2011, 519, 4798-4803.

18 Y. Y. Wu, X. H. Wang, C. F. Zhong and L. T. Li, Effect of anneal conditions on electrical properties of Mn-Doped $\left(\mathrm{Na}_{0.85} \mathrm{~K}_{0.15}\right)_{0.5} \mathrm{Bi}_{0.5} \mathrm{TiO}_{3}$ thin films prepared by sol-gel method, J. Am. Ceram. Soc., 2011, 94, 1843-1849.

$19 \mathrm{~S}$. T. Zhang, B. Yang and W. Cao, The temperaturedependent electrical properties of $\mathrm{Bi}_{0.5} \mathrm{Na}_{0.5} \mathrm{TiO}_{3}-\mathrm{BaTiO}_{3}$ $\mathrm{Bi}_{0.5} \mathrm{~K}_{0.5} \mathrm{TiO}_{3}$ near the morphotropic phase boundary, Acta Mater., 2012, 60, 469-475.

20 W. Li, H. Zeng, J. Hao and J. Zhai, Enhanced dielectric and piezoelectric properties of $\mathrm{Mn}$ doped $\left(\mathrm{Bi}_{0.5} \mathrm{Na}_{0.5}\right) \mathrm{TiO}_{3}$ $\left(\mathrm{Bi}_{0.5} \mathrm{~K}_{0.5}\right) \mathrm{TiO}_{3}-\mathrm{SrTiO}_{3}$ thin films, J. Alloys Compd., 2013, 580, 157-161.

21 W. H. Cui, X. H. Wang and L. T. Li, Large piezoresponse of $\mathrm{Na}_{0.5} \mathrm{Bi}_{0.5} \mathrm{TiO}_{3}-\mathrm{K}_{0.5} \mathrm{Bi}_{0.5} \mathrm{TiO}_{3}$ thin films prepared via waterbased sol-gel method, Ceram. Int., 2015, 41, S37-S40.

22 Y. H. Jeon, E. A. Patterson, D. P. Cann, P. Mardilovich, W. Stickel, B. J. Gibbons and S. Zhang, Large piezo response and ferroelectric properties of $\left(\mathrm{Bi}_{0.5} \mathrm{Na}_{0.5}\right) \mathrm{TiO}_{3}$ $\left(\mathrm{Bi}_{0.5} \mathrm{~K}_{0.5}\right) \mathrm{TiO}_{3}-\mathrm{Bi}\left(\mathrm{Mg}_{0.5} \mathrm{Ti}_{0.5}\right) \mathrm{O}_{3}$ thin films prepared by chemical solution deposition, J. Am. Ceram. Soc., 2013, 96, 2172-2178.

23 Y. Y. Wu, X. H. Wang and L. T. Li, Effect of Sc-doping on structure and electrical properties of $\left(\mathrm{Na}_{0.85} \mathrm{~K}_{0.15}\right)_{0.5} \mathrm{Bi}_{0.5} \mathrm{TiO}_{3}$ thin films prepared by sol-gel processing, J. Am. Ceram. Soc., 2011, 94, 2518-2522.

24 Z. K. Xie, Z. X. Yue, B. Peng, J. Zhang, C. Zhao, X. H. Zhang, G. Rueh and L. T. Li, Large enhancement of the recoverable energy storage density and piezoelectric response in relaxorferroelectric capacitors by utilizing the seeding layers engineering, Appl. Phys. Lett., 2015, 106, 202901.

25 Q. G. Chi, J. F. Dong, C. H. Zhang, Y. Chen, X. Wang and Q. Q. Lei, A simple, low-temperature fabrication method of highly (100)-oriented $\left(\mathrm{Na}_{0.85} \mathrm{~K}_{0.15}\right)_{0.5} \mathrm{Bi}_{0.5} \mathrm{TiO}_{3}$ thin films with outstanding electric properties, J. Alloys Compd., 2017, 704, 336-342.

26 J. Li, J. Yu, G. Peng, Y. B. Wang and W. L. Zhou, The influence of the thickness of $\mathrm{TiO}_{2}$ seeding layer on structural and electrical properties of $\mathrm{Bi}_{3.15} \mathrm{Nd}_{0.85} \mathrm{Ti}_{3} \mathrm{O}_{12}$ thin films, J. Phys. D: Appl. Phys., 2007, 40, 3788-3792.

27 K. Aoki, Y. Fukuda and K. Numata, Effects of titanium buffer layer on lead-zirconate-titanate crystallization processes in sol-gel deposition technique, Jpn. J. Appl. Phys., Part 1, 1995, 34, 192-195.

28 Z. G. Li, Y. X. Wu and S. Miyake, Metallic sputtering growth of high quality anatase phase $\mathrm{TiO}_{2}$ films by inductively coupled plasma assisted DC reactive magnetron sputtering, Surf. Coat. Technol., 2009, 203, 3661-3668. 
29 K. Karthik, S. K. Pandian and N. V. Jaya, Effect of nickel doping on structural, optical and electrical properties of $\mathrm{TiO}_{2}$ nanoparticles by sol-gel method, Appl. Surf. Sci., 2010, 256, 6829-6833.

30 A. Sasaki, T. Chiba, Y. Mamiya and E. Otsuki, Dielectric and Piezoelectric Properties of $\left(\mathrm{Bi}_{0.5} \mathrm{Na}_{0.5}\right) \mathrm{TiO}_{3}-\left(\mathrm{Bi}_{0.5} \mathrm{~K}_{0.5}\right) \mathrm{TiO}_{3}$ Systems, Jpn. J. Appl. Phys., Part 1, 1999, 38, 5564-5567.

31 C. R. Cho, W. J. Lee, B. G. Yu and B. W. Kim, Dielectric and ferroelectric response as a function of annealing temperature and film thickness of sol-gel deposited $\mathrm{Pb}\left(\mathrm{Zr}_{0.52} \mathrm{Ti}_{0.48}\right) \mathrm{O}_{3}$ thin film, J. Appl. Phys., 1999, 86, 2700.

32 D. V. Taylor and D. Damjanovic, Evidence of domain wall contribution to the dielectric permittivity in PZT thin films at sub-switching fields, J. Appl. Phys., 1997, 82, 1973.

33 B. J. Chu, X. Zhou, K. L. Ren, B. Neese, M. R. Lin, Q. Wang, F. Bauer and Q. M. Zhang, A dielectric polymer with high electric energy density and fast discharge speed, Science, 2006, 313, 334-336.
34 Z. Xie, B. Peng, S. Meng, Y. Zhou, Z. Yue and S. E. TrolierMcKinstry, High-energy-storage density capacitors of $\mathrm{Bi}\left(\mathrm{Ni}_{1 / 2} \mathrm{Ti}_{1 / 2}\right) \mathrm{O}_{3}-\mathrm{PbTiO}_{3}$ thin films with good temperature stability, J. Am. Ceram. Soc., 2013, 96, 2061-2064.

35 G. Viola, H. Ning, M. J. Reece, R. Wilson, T. M. Correia, P. Weaver, M. G. Cain and H. Yan, Reversibility in electric field-induced transitions and energy storage properties of bismuth-based perovskite ceramics, J. Phys. D: Appl. Phys., 2012, 45, 355302.

36 L. H. Luo, B. Y. Wang, X. X. Jiang and W. P. Li, Energy storage properties of $(1-x)\left(\mathrm{Bi}_{0.5} \mathrm{Na}_{0.5}\right) \mathrm{TiO}_{3}-x \mathrm{KNbO}_{3} \quad$ lead-free ceramics, J. Mater. Sci., 2014, 49, 1659-1665.

37 F. Gao, X. L. Dong, C. L. Mao, F. Cao and G. S. Wang, c/ a ratio-dependent energy-storage density in (0.9- $x$ ) $\mathrm{Bi}_{0.5} \mathrm{Na}_{0.5} \mathrm{TiO}_{3}-x \mathrm{BaTiO}_{3}-0.1 \mathrm{~K}_{0.5} \mathrm{Na}_{0.5} \mathrm{NbO}_{3}$ ceramics, J. Am. Ceram. Soc., 2011, 94, 4162-4164. 